\title{
A versatile ribosomal protein promoter-based reporter system for selective assessment of RNA stability and post-transcriptional control
}

\author{
EDWARD HITTI, ${ }^{1,3}$ SUHAD AL-YAHYA, ${ }^{1,3}$ MAHER AL-SAIF, ${ }^{1,3}$ PEER MOHIDEEN, ${ }^{1}$ LINAH MAHMOUD, ${ }^{1}$ \\ STEPHEN J. POLYAK, ${ }^{2}$ and KHALID S.A. KHABAR ${ }^{\mathbf{1}}$ \\ ${ }^{1}$ Program in BioMolecular Research, King Faisal Specialist Hospital and Research Center, Riyadh, Saudi Arabia 11211 \\ ${ }^{2}$ Department of Laboratory Medicine, University of Washington, Seattle, Washington 98195, USA
}

\begin{abstract}
Assessment of post-transcriptional control relies on use of transcriptional inhibitors and is masked by copious and cryptic transcriptional induction. We screened several cellular promoters that are constitutively active yet noninducible to external stimuli. The ribosomal protein RPS30 promoter was chosen; its TATA signal and sp1 site location were optimized. The modified promoter (RPS30M) is selective to post-transcriptional effects of AU-rich elements (ARE) in the 3'UTR, while it is not transcriptionally responsive to a wide variety of agents including pro-inflammatory cytokines and RNA-binding proteins. Specific cis-acting elements can be appended to RPS30M by a cloning-free approach to allow coupled transcriptional/post-transcriptional assessment, as demonstrated with NF- $\mathrm{KB}$ and $\beta$-catenin/wnt signaling experiments. Moreover, efficient tetracycline-regulated RPS30M was created for quantitative assessment of the half-lives of mRNAs containing AREs. The described approach provides enhanced versatility and suitability for selective post-transcriptional assessment with or without transcriptional induction.
\end{abstract}

Keywords: post-transcriptional control; RNA stability; AU-rich elements; reporter systems

\section{INTRODUCTION}

Post-transcriptional regulation of gene expression, which has gained further attention in recent years, is essential for normal functioning of eukaryotic cells, and aberrations in this regulation can contribute to certain disease processes (Fan et al. 2005; Khabar 2005). Unlike reporter assays for transcriptional analysis that are widely used, there is a need for selective and versatile post-transcriptional regulation assessment systems.

The $3^{\prime}$ untranslated region ( $3^{\prime} \mathrm{UTR}$ ) of eukaryotic mRNA is a major target for transacting factors, such as RNAbinding proteins or miRNAs that affect the stability or the translation of specific mRNAs (Glisovic et al. 2008; Hobert 2008; Bartel 2009; Zhang and Su 2009). The 3'UTRs often contain cis-acting elements that mediate post-transcriptional control of gene expression including RNA stability and

\footnotetext{
${ }^{3}$ These authors contributed equally to this work.

Reprint requests to: Khalid S.A. Khabar, Program in BioMolecular Research, King Faisal Specialist Hospital and Research Center, Riyadh, Saudi Arabia 11211; e-mail: khabar@kfshrc.edu.sa; fax: 966-1-4427876.

Article published online ahead of print. Article and publication date are at http://www.rnajournal.org/cgi/doi/10.1261/rna.2026310.
}

translation. Among these sequences are the AU-rich elements (AREs) that are found in more than $10 \%$ of the human or mouse genome (Halees et al. 2008).

ARE-mediated pathways are responsive to inflammatory stimuli like endotoxin, pro-inflammatory cytokines, and other stress inducers. The signals are transduced to the ARE mainly through signaling cascades, such as the p38 MAPK pathway that phosphorylates ARE-binding proteins like tristetraprolin (Wang et al. 1999; Winzen et al. 1999; Lasa et al. 2000; Chrestensen et al. 2004; Hitti et al. 2006). The same stimuli are also strong inducers of a wide range of promoters including the most commonly used exogenous expression viral promoters CMV and SV40 (Lee et al. 2004; Ramanathan et al. 2005). The inducibility of these promoters may mask true post-transcriptional assessment in reporter assays.

In order to study selective post-transcriptional effects on gene expression, we developed an EGFP reporter expression system that relies on a constitutively active cellular promoter that is noninducible by external stimuli. This is different from the behavior of viral promoters such as CMV and SV40 virus that harbor binding sites for transcription factors that are activated by different signaling 
pathways. This system also allows the use of convenient fluorescence-based reporter assay rather than methods that are based on the inhibition of transcription and mRNA detection. Inhibition of transcription by drugs like actinomycin D can cause significant nonspecific effects, such as toxicity, especially for mRNAs with long half-lives, and enhancement of mRNA stability in certain conditions (Rajagopalan and Malter 1996; Blaxall and Port 2000). In this paper, we used ribosomal protein RPS30 promoter that was further modified for increased strength. Furthermore, transcriptional responsive elements can be added to RPS30M by a simple cloning-free strategy to allow coupled transcriptional and post-transcriptional effects. Moreover, the RPS30M can be rendered TetO-regulated allowing transcriptional block and mRNA half-life determination. We propose a versatile and enhanced system for the analysis of post-transcriptional and coupled transcriptional/posttranscriptional regulation that is suitable for both in-depth analysis and large-scale screening efforts.

\section{RESULTS AND DISCUSSION}

\section{Screening for noninducible and strong cellular promoters}

Several cellular promoters were assessed for their expression strength and responsiveness to the pro-inflammatory cytokine TNF- $\alpha$. First, we selected several candidate cellular promoters from microarray experiments and bioinformatics (Al-Zoghaibi et al. 2007) that have strong expression signals or EST counts, respectively. We have found in microarray screening experiments that the selected cellular gene promoters, particularly those of ribosomal protein genes, namely, RPLO, RPL1, RPL3, RPS23, and RPS30, are abundantly expressed in different cell types, their expression does not change with different stimuli, and they do not contain inducible transcriptional elements, such as those of NF- $\kappa B$ sites (data not shown). The CMV and SV40 minimal promoters, commonly used viral promoters in reporter gene assays, were used as controls. The elongation factor $\alpha$ (EEF1A1) promoter was used as a control cellular promoter. The promoters were amplified from genomic DNA and cloned upstream of EGFP in a mammalian expression vector (Fig. 1A).

The EGFP reporter fluorescence, generated from HEK293 cells that were transfected with each of the promoter constructs, was assessed. As expected the CMV promoter gave the highest expression (Fig. 1B, inset with different scale) when compared with cellular promoters-about 10fold $(P<0.001)$. The minimal SV40 promoter, commonly used in reporter constructs was weakly expressed. The cellular promoters derived from EEF1A with its first intron or with the eIF4g intron gave higher expression than the ribosomal protein genes ( $R P L O, R P L 1$, and RPL3) - these promoters also contain their first introns. Since introns are known to enhance transgenic expression by increasing mRNA accumulation (Nott et al. 2003), we tested this effect on RPS23 promoter-linked expression. The intron of RPS23 (RPS23I) enhanced the expression of RPS23 promoter-linked reporter activity by eightfold $(P<0.001)$ (Fig. 1B). The RPS30 that also contains its first intron caused higher expression than RPS23. Both RPS23 and RPS30 promoters had the highest expression level of all cellular promoters tested here.

The CMV was strongly responsive to TNF- $\alpha$ induction (2.2-fold) (Fig. 1B, inset). The SV40 minimal promoter was increased by 2.3 -fold due to TNF- $\alpha$ treatment. Unlike CMV and SV40, all the ribosomal protein promoters including RPS30 were not responsive to TNF- $\alpha$. The inducibility was also tested at the mRNA level by real-time (RT) PCR; in contrast to CMV, the RPS30 promoter was neither responsive to TNF- $\alpha$ nor IL1- $\alpha$ (Fig. 1C). Because of its enhanced expression and lack of cytokine stimulation, we focused on the RPS30 promoter for further evaluation and suitability in post-transcriptional assessment assays.

\section{Modification of the RPS30 promoter and response to stimuli}

Post-transcriptional gene regulation can lead to a substantial reduction in mRNA or protein levels. Therefore, the need of a promoter with a sustained high level of detectable expression is crucial. A modification was made to the RPS30 promoter to make it stronger. In the modified RPS30 (RPS30M), the TATA-like box was replaced with the canonical TATA signal and the promoter was truncated to minimize potential transcriptional induction while bringing the distant sp1 site toward the transcriptional start site for higher constitutive expression (Fig. 2A). The modified RPS30M was clearly stronger (approximately ninefold) than the wild-type RPS30 (Fig. 2B). Although intratest transfection efficiency variation is always low $(<6 \% \mathrm{CV})$, normalization by cotransfection with red fluorescent protein (RFP) was performed and yielded similar results (data not shown). Likewise, RPS23 with the modification in a similar manner as with RPS30 was superior to the wild-type RPS23 (Fig. 2B).

We tested the responsiveness of the RPS30M and CMV promoters to a variety of external stimuli that triggers different signaling cascades like dsRNA (an RNA viral intermediate analog), $\mathrm{H}_{2} \mathrm{O}_{2}$ (oxidative stress), lithium ( $\beta$-catenin pathway), calyculin (phosphatase inhibitor), $\mathrm{CoCl}_{2}$ (hypoxia), PMA (protein kinase $\mathrm{C}$ inducer), ionomycin (calcium signaling), and the p38 mitogen-activated protein kinase activator, anisomycin (Fig. 2C). Unlike $\mathrm{CMV}$, the RPS30M promoter was not responsive to all inducers except the combination of PMA and ionomycin, where the response was weak and statistically nonsignificant $(P=0.174)$ when compared with the CMV promoter.

Further, we performed experiments to test the ability of the RPS30M system to specifically detect post-transcriptional 


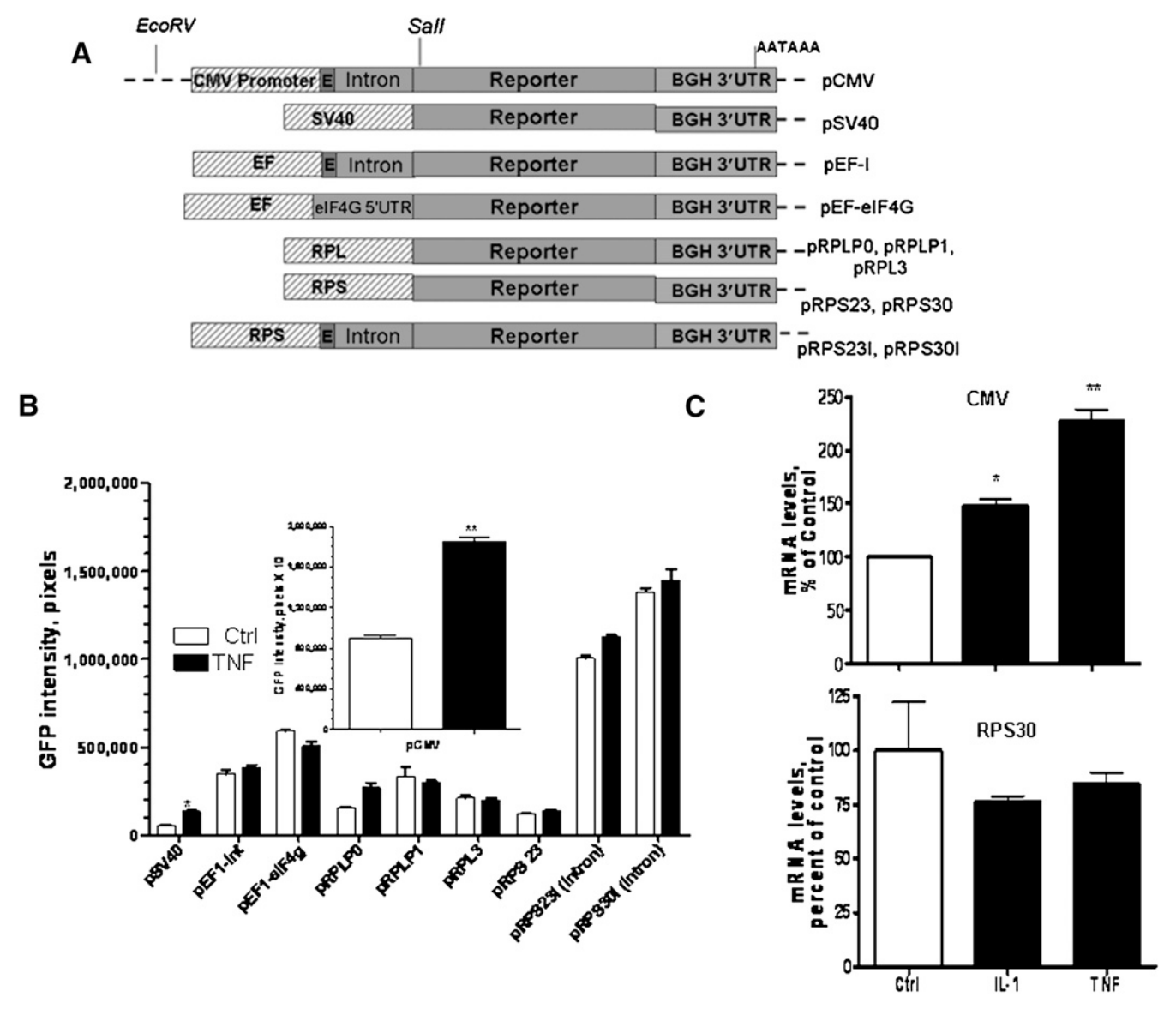

FIGURE 1. Construction and performance of cellular promoter vectors. (A) Schematic representation of the promoter constructs and their forms. The vector constructs comprise different promoters (dashed boxes), EGFP reporter coding region, and the stable BGH 3'UTR. pCMV contains the CMV promoter with intron A; pSV40 contains the SV40 promoter; pEF1 contains the elongation factor $\alpha$ promoter with or without the eIF4G 5'UTR; pRPL contains the ribosomal protein gene promoters of RPL0, RPL1, and RPL30; and pRPS contains the ribosomal protein gene promoters of RPS23 or RPS30 with or without their first introns (I). (B) Analysis of promoter strength and inducibility. HEK293 cells in 96-well microplates were transfected with the indicated promoter constructs (100 ng DNA) for $18 \mathrm{~h}$ and then treated with or without TNF- $\alpha$ (10 ng/mL) for an additional $18 \mathrm{~h}$. Reporter activity as fluorescence was assessed from images captured by a BD automated Bioimager and quantitated by ProXcell as described in Materials and Methods. Readings are mean \pm SEM of fluorescence intensities from quadruplicate wells. CMV promoter data are shown independently because it has a higher scale. $(C)$ The response of CMV and the RPS30 promoters at mRNA levels. HEK293 cells were transfected with CMV and RPS30 constructs overnight and treated with TNF- $\alpha$ or IL- $1 \alpha$ for $4 \mathrm{~h}$. Total RNA was extracted at the indicated time points and subjected to RT-PCR using a primer pair/TaqMan probe specific to EGFP mRNA. The TaqMan primer/probe spans an intron and exon junction sequence for efficient control of DNA contamination. Data are mean \pm SEM of three independent experiments. ${ }^{\star} P<0.05$. ${ }^{\star \star} P<0.01$.

regulation due to pro-inflammatory cytokines. First, we evaluated the reporter response to the presence of the mRNA destabilization elements, ARE, and found that they have a better suppressive response on the reporter activity from the RPS30M-linked construct when compared with the reporter activity from the CMV promoter construct (Fig. 2D). The EGFP reporter under the control of the RPS30M promoter and linked to the stable BGH 3'UTR that lacks ARE, was not responsive in the HEK293 cell line to either interleukin-1 (IL-1 $\alpha$ ), okadaic acid (OA), or a combination of both agents (Fig. 2E). In contrast, when the same reporter is fused to the ARE-containing IL-8 $3^{\prime}$ UTR and TNF- $\alpha$ 3'UTR, a strong and significant selective response to $\mathrm{OA}$ or OA in combination with IL- $1 \alpha$ could be detected (Fig. 2E). OA is an inhibitor of protein phosphatase 1 and $2 \mathrm{~A}$ and can increase ARE-containingmRNA stability, possibly by the inhibition of TTP dephosphorylation leading to TTP phosphorylation and loss of its mRNA-binding action (Pshenichkin and Wise 1995; Benjamin et al. 2004; Hitti et al. 2006).

The experiments above indicate that the RPS30M system is suitable for the study of selective post-transcriptional regulation in response to a wide range of stimuli including pro-inflammatory inducers.

\section{The assessment of post-transcriptional regulation using the RPS30 system}

The RPS30M system was tested using another cell line, Huh-7. This well-differentiated hepatocellular cell line 
A
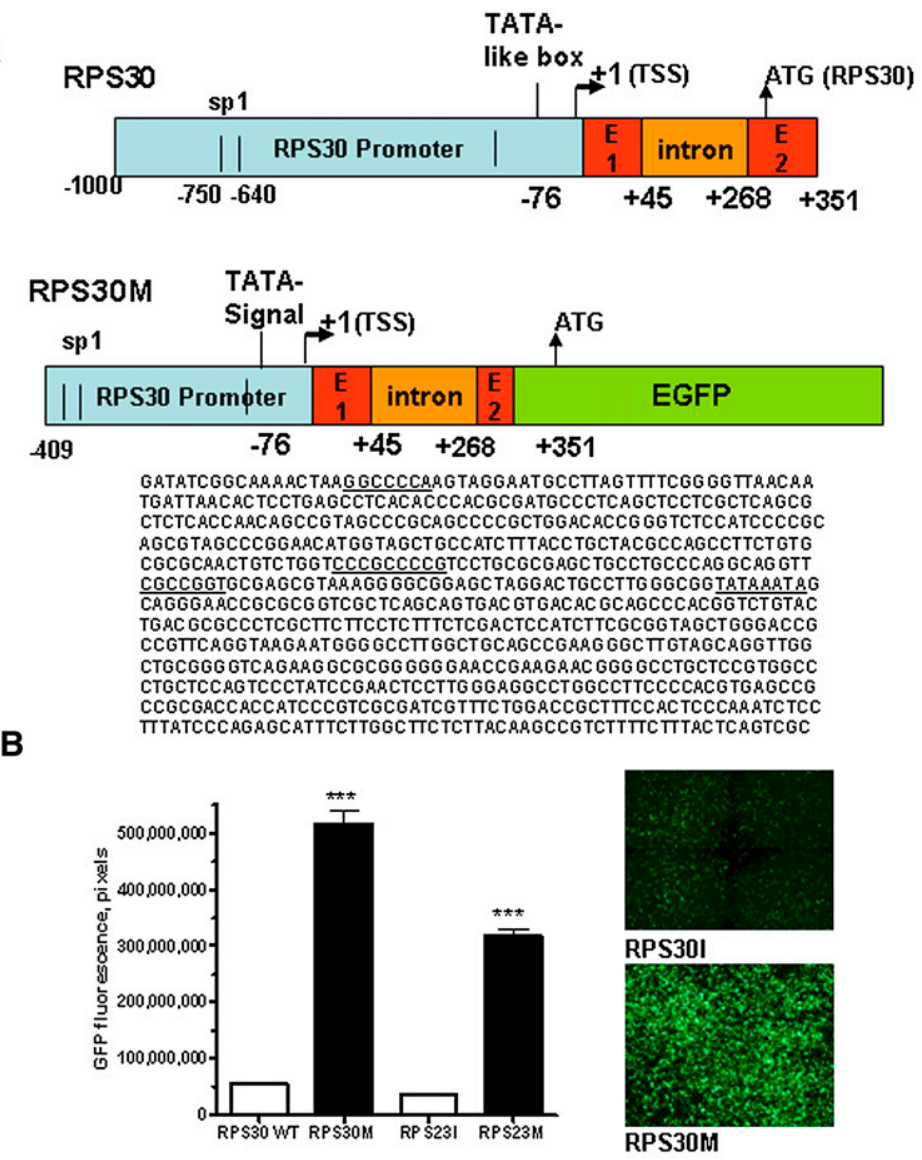

C

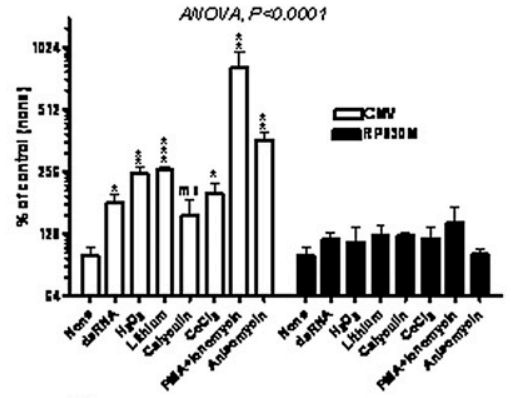

D

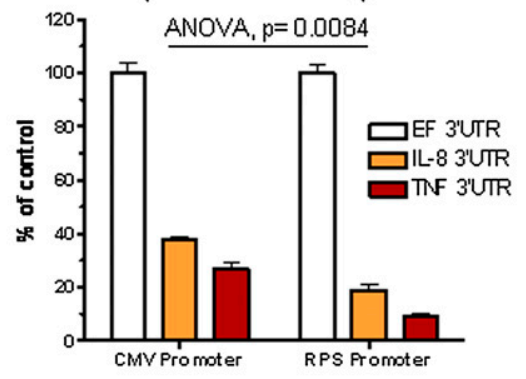

E

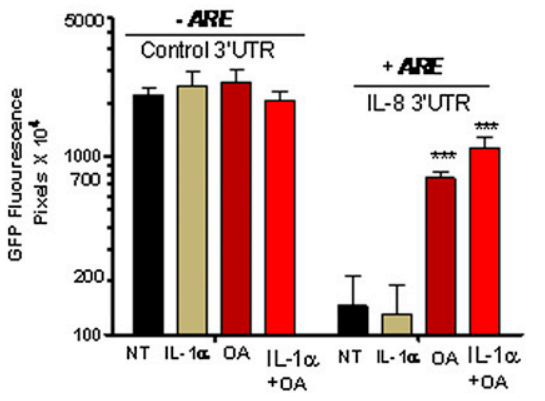

FIGURE 2. Modification and performance of the RPS23 and RPS30 promoters. (A) Schematic diagram of the RPS30 promoter and its modifications in RPS30M. Numbers show the nucleotide position in relation to the transcriptional start site (TSS). Vertical lines indicate positions of sp1 sites. E: exon. Vertical arrow is translational start. (Lower panel) The sequences of the modified promoter, underlined are sp1 sites and modified TATA signal. (B) Effects of RPS modifications on reporter expression in HEK293. Cells were transfected with $100 \mathrm{ng}$ of the reporters for $18 \mathrm{~h}$; images were captured by an automated BD Bioimager and quantitated by ProXcell. $(C)$ Response of CMV and RPS30M promoters to several external stimuli and signaling inducers. HEK293 cells in 96-well microplates were transfected with CMV and RPS30M constructs that harbor the stable BGH 3'UTR and treated with the indicated inducers overnight. (D) Response of RPS promoter-linked reporter to ARE-3'UTR. HEK293 cells were transfected with $150 \mathrm{ng}$ of EGFP reporter vectors that are under the transcriptional control of the ribosomal protein RPS30M or CMV promoter. The EGFP reporter contains either control stable 3'UTR or 3'UTR, which contain 200 bases of IL-8 or TNF- $\alpha 3^{\prime}$ UTR that

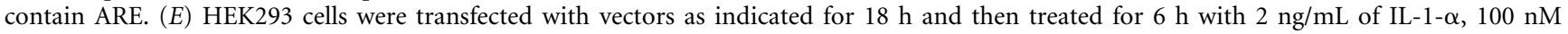
okadaic acid $(\mathrm{OA})$ or a combination. Reporter activity as fluorescence was assessed from high resolution images captured by a BD Bioimager and quantitated by ProXcell as described in Materials and Methods. All data above are mean \pm SEM (quadruplicate) of one of three experiments. ${ }^{\star} P<$ $0.02,{ }^{* *} P<0.01,{ }^{* * *} P<0.001$.

responds to a variety of pro-inflammatory cytokines and has been customarily used for hepatitis and cytokine research (Bevan and Raynes 1991; Preiss et al. 2008; AitGoughoulte et al. 2009). An additional advantage of Huh-7 is its excellent transfection efficiency $(\sim 70 \%)$. In the case of the BGH-3'UTR that lacks the ARE, no or minimal induction by the cytokines, $\mathrm{OA}$, or combination was observed at the mRNA level (Fig. 3A, left panel). With the reporter constructs that are fused with IL-8 $3^{\prime}$ UTR or TNF $3^{\prime}$ UTR, treatment with IL- $1 \alpha$ or TNF- $\alpha$ led to an increase (from two- to threefold) in the reporter mRNA levels and no further increase was observed with addition of OA (Fig. 3A, middle, right panels).
Despite the increased effects, due to cytokine treatment, on reporter mRNA levels from the ARE-3'UTR constructs (Fig. 3B, middle, right panels), treatment with the cytokines had minimal effects on the protein expression (Fig. 3B, middle, right panels). It has been shown that the ARE can mediate blockage of the ARE-mRNA translation, and release from blockage can be mediated by certain inducers (Zhang et al. 2002; Vasudevan et al. 2007). Indeed, treatment with $\mathrm{OA}$ and particularly in combination with IL- $1 \alpha$ or TNF- $\alpha$ led to a considerable up-regulation of protein expression (from 4.0- to 5.5-fold) (Fig. 3B, middle, right panels) suggesting that combined $\mathrm{OA}$ and cytokine treatment releases a translation block. 

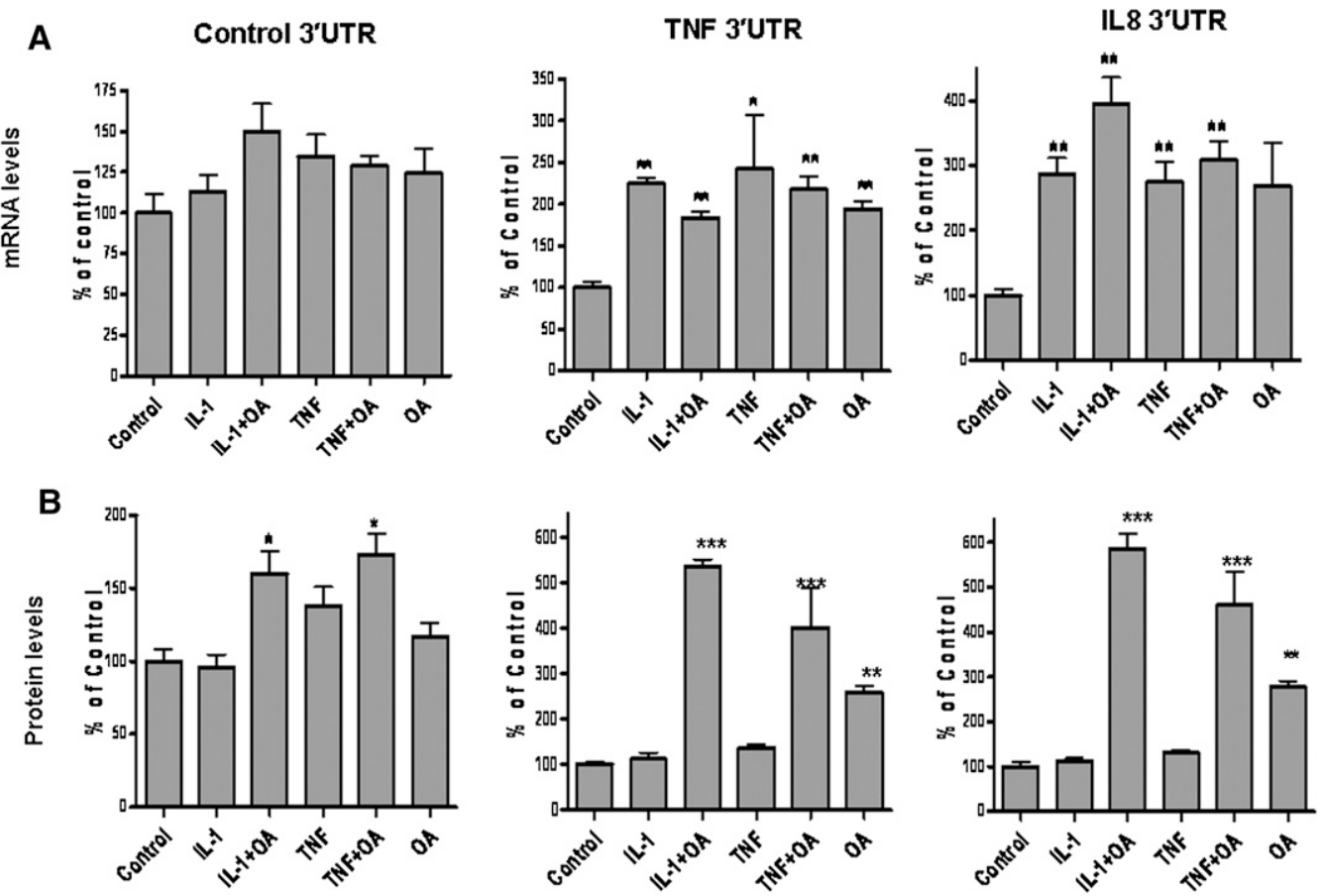

FIGURE 3. The effect of pro-inflammatory cytokines on the RPS30M-driven post-transcriptional reporter system. HuH-7 cells were transfected with vectors containing the RPS30M promoter-linked EGFP constructs fused with the control non-ARE BGH 3'UTR, IL8 3'UTR, or TNF- $\alpha$ $3^{\prime}$ UTR. Cells were treated with $2 \mathrm{ng} / \mathrm{mL}$ of IL $1 \alpha, 2 \mathrm{ng} / \mathrm{mL}$ of TNF- $\alpha, 100 \mathrm{nM}$ okadaic acid (OA) or a combination as indicated. Fluorescence due to the activity of the EGFP protein $(A)$ was quantified by imaging (after $6 \mathrm{~h}$ ) and the mRNA levels $(B)$ were quantified by real-time QPCR after $4 \mathrm{~h}$. Mean \pm SEM of three independent experiments. ${ }^{\star} P<0.02,{ }^{\star \star} P<0.01,{ }^{* *} P<0.001$.

The RPS30M reporter system with a fluorescence end point allows the assessment of the integrated outcome of mRNA stability and translation, and thus, it is more relevant in drug screening approaches. Using the EGFP-based assay and the Taqman RT-PCR permits analysis of mRNA stabilization and the regulation of translation in a single reporter assay.

\section{RPS30M-based post-transcriptional assessment of RNA-binding protein activity}

Because RNA-binding proteins can affect a number of transcriptional factors as evidenced from microarray studies (Lal et al. 2004; Lopez de Silanes et al. 2005; Lai et al. 2006; Winzen et al. 2007; Stoecklin et al. 2008), selective post-transcriptional assessment of their effect on reporter constructs is usually performed using transcriptional inhibitors. Thus, the RPS30M-based model is a practical alternative to study selective post-transcriptional effects of RNA-binding proteins without secondary transcriptional effects.

HuH-7 cells were cotransfected with RPS30M-EGFP reporter vector and either empty pcDNA3.1 or pcDNA3.1 expressing the ARE-binding and stabilizing protein $\mathrm{HuR}$ and the dominant negative form of TTP, C124R, which stabilizes ARE-mRNA (Lai et al. 2000; Franks and LykkeAndersen 2007; Al-Ahmadi et al. 2009). Recently, we showed that C124R TTP has a stabilizing effect on mRNAs with ARE-containing HuR 3'UTR (Al-Ahmadi et al. 2009). We also observed a nonspecific effect of C124R TTP and HuR on the CMV promoter. There was increased activity from the reporter gene fused with the control 3'UTR (no ARE) driven by the CMV promoter due to overexpression of C124R TTP and HuR, fivefold and 2.5-fold, respectively (Fig. 4A). In contrast, neither HuR nor C124R TTP has nonspecific effects on RPS30M promoter activity (Fig. 4A). Increased expression of EGFP, due to the effect of the RNAbinding proteins, was observed only when the reporter was linked to IL-8 and TNF 3'UTRs (Fig. 4B,C).

To further confirm the specificity of the effect of C124R TTP on ARE itself, it was tested against the 60 nucleotides (nt) of ARE derived from TNF- $\alpha 3^{\prime}$ UTR and a mutated form of this region. The effect of the TTP zinc finger mutant was observed only with the wild-type but not the mutant, ARE (Fig. 4D).

\section{Transcriptionally coupled assessment of post-transcriptional regulation}

A useful variation of the RPS30M promoter-linked reporter system is the ability to append any inducible cis-acting transcriptional response element (TRE) to study single or coupled transcriptional and post-transcriptional effects employing a simplified and versatile cloning-free approach 


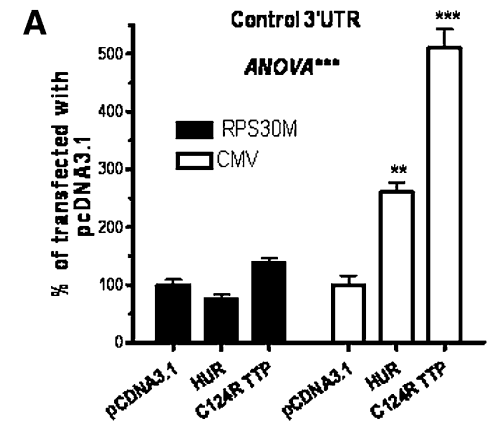

B

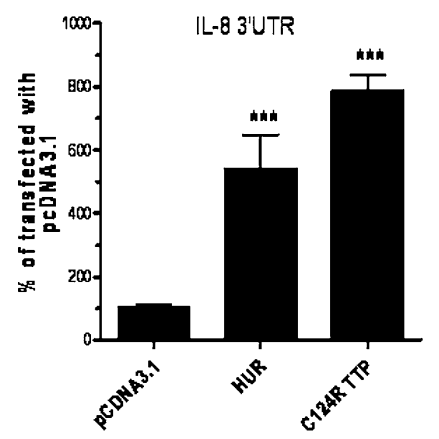

C

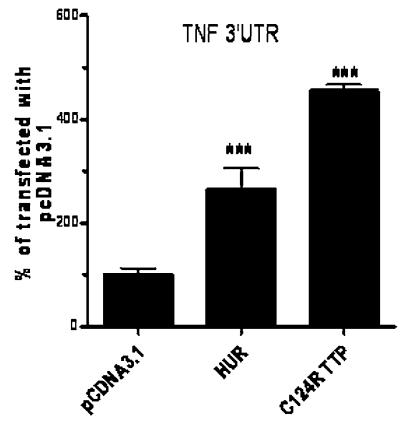

D

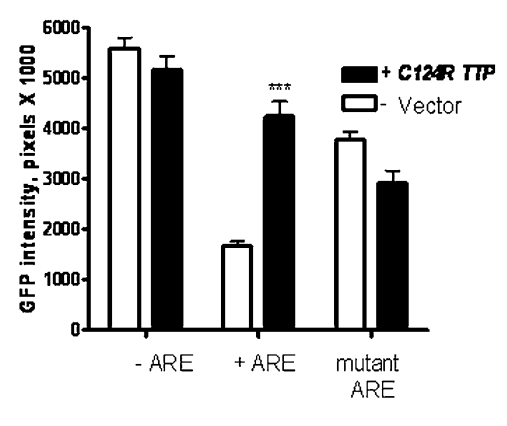

FIGURE 4. The effect of RNA-binding proteins on the RPS30M-driven reporter system on post-transcriptional regulation. Huh-7 cells in 96-well microplates were cotransfected with $50 \mathrm{ng}$ reporter vector with either empty pcDNA3.1 vector, or pcDNA3 expressing HuR, or a dominant negative RNA stabilizing mutant form of TTP $(C 124 R)$. The reporter constructs are fused with $(A)$ RPS30M or CMV-driven EGFP with the control BGH $3^{\prime}$ UTR that lacks AREs; (B) RPS30M-driven reporter fused with IL8 3'UTR; or $(C)$ RPS30M-driven reporter fused with TNF- $\alpha$ 3'UTR; or (D) RPS30M-driven fused with TNF- $\alpha 60 \mathrm{nt}$ ARE, or its mutant form. ${ }^{\star * \star} P<0.001$.

(Fig. 5A; al-Haj et al. 2009). We constructed linear reporters that have Tcf/lef sequence elements that respond to the $\beta$-catenin/wnt pathway inducer, lithium chloride (Hedgepeth et al. 1997). Lithium inhibits glycogen synthase kinase $3 \beta$ resulting in the cytoplasmic accumulation of $\beta$-catenin and movement into the nucleus to bind Tcf/lef transcription factors that activate Tcf/lef TRE-containing target genes (Pap and Cooper 1998). The $\beta$-catenin/wnt pathway also regulates the stability of a number of mRNAs like PITX2, c-Jun, cyclin D1, and cyclin D2, in an AREdependent manner (Briata et al. 2003; Gherzi et al. 2006).

HEK-293 cells were transfected with Tcf/lef reporter constructs and then treated with different concentrations of lithium. At the transcriptional level, a dose response ( $r=$ $0.98, P<0.001)$ was observed when the Tcf/lef TRE was linked to a truncated (RPS30M -68) and to a full-length RPS30M promoter (Fig. 5A,B). In the absence of Tcf/lef TRE, the RPS30M promoter was not induced by lithium, except at the high concentration of $30 \mathrm{mM}$, where a slight but statistically nonsignificant induction was seen (Fig. 5B). A RPS30M-driven construct with TNF 3'UTR was responsive to lithium, indicating selective post-transcriptional action of the $\beta$-catenin induced pathway (Fig. 5C, left side). To analyze coupled transcriptional and post-transcription regulation in response to the same stimuli, we compared

the effect of lithium on constructs with or without the Tcf/lef TRE fused to the RPS30M promoter in the presence or absence of TNF- $\alpha$ 3'UTR (Fig. 5C, right side). Interestingly, transcriptional induction alone (Tcf/lef TRE-RPS30M in the absence of TNF 3'UTR with $20 \mathrm{mM}$ lithium) increased reporter activity 2.5fold (Fig. 5B) whereas post-transcriptional induction alone increased reporter activity by fivefold (Fig. 5C). The coupled transcriptional and post-transcriptional effect (Tcf/lef TRE-RPS30M with TNF- $\alpha$ 3'UTR) leads to more than 10-fold induction of the EGFP reporter (Fig. 5C). These results suggest that the coupled effect is at least additive and can be synergistic.

The RPS30M transcriptional/posttranscriptional coupled system was also used to analyze response to IL- $1 \alpha$. This cytokine activates the NF- $\mathrm{BB}$ signaling pathway to induce transcription of many inflammation related genes, as well as the p38 MAPK signaling pathway, which stabilizes and enhances the translation of ARE containing mRNAs. The effect of IL- $1 \alpha$ treatment on reporter constructs in HEK293 cells in the presence or absence of NF- $\mathrm{KB}$ TRE sites with or without IL-8 $3^{\prime}$ UTR was analyzed. Similar to the $\beta$-catenin/wnt pathway, enhanced coupled transcriptional/ post-transcriptional effects were observed. The presence of NF- $\kappa \mathrm{B}$ TRE increased the reporter levels due to IL- $1 \alpha$ treatment by 1.7 -fold; and when the IL8 3'UTR is present, the coupled transcriptional/post-transcriptional effect increased to more that 2.5-fold (Fig. 5D). Parallel experiments were performed using truncated forms of RPS30M ( -68 RPS30M and -168 RPS30M) fused or not fused to NF- $\kappa B$ TRE and in the presence or absence of TNF- $\alpha$ 3'UTR. As expected the coupled effect was observed particularly with the -68 RPS30M (Fig. 5E). These results show that the RPS30M system is versatile and can be used to study transcriptional, post-transcriptional, and coupled processes.

\section{TetO-regulated RPS30M promoter for assessment of post-transcriptional effects}

RPS30M promoter-driven expression can become regulated by fusing the promoter to TetO elements, which bind a transactivator that is inactivated by doxycycline. We used the cloning-free approach (Fig. 5A) to generate TetO -24 RPS30 and TetO -68 RPS30 promoter fusion constructs. We first evaluated the performance and degree of leakiness 

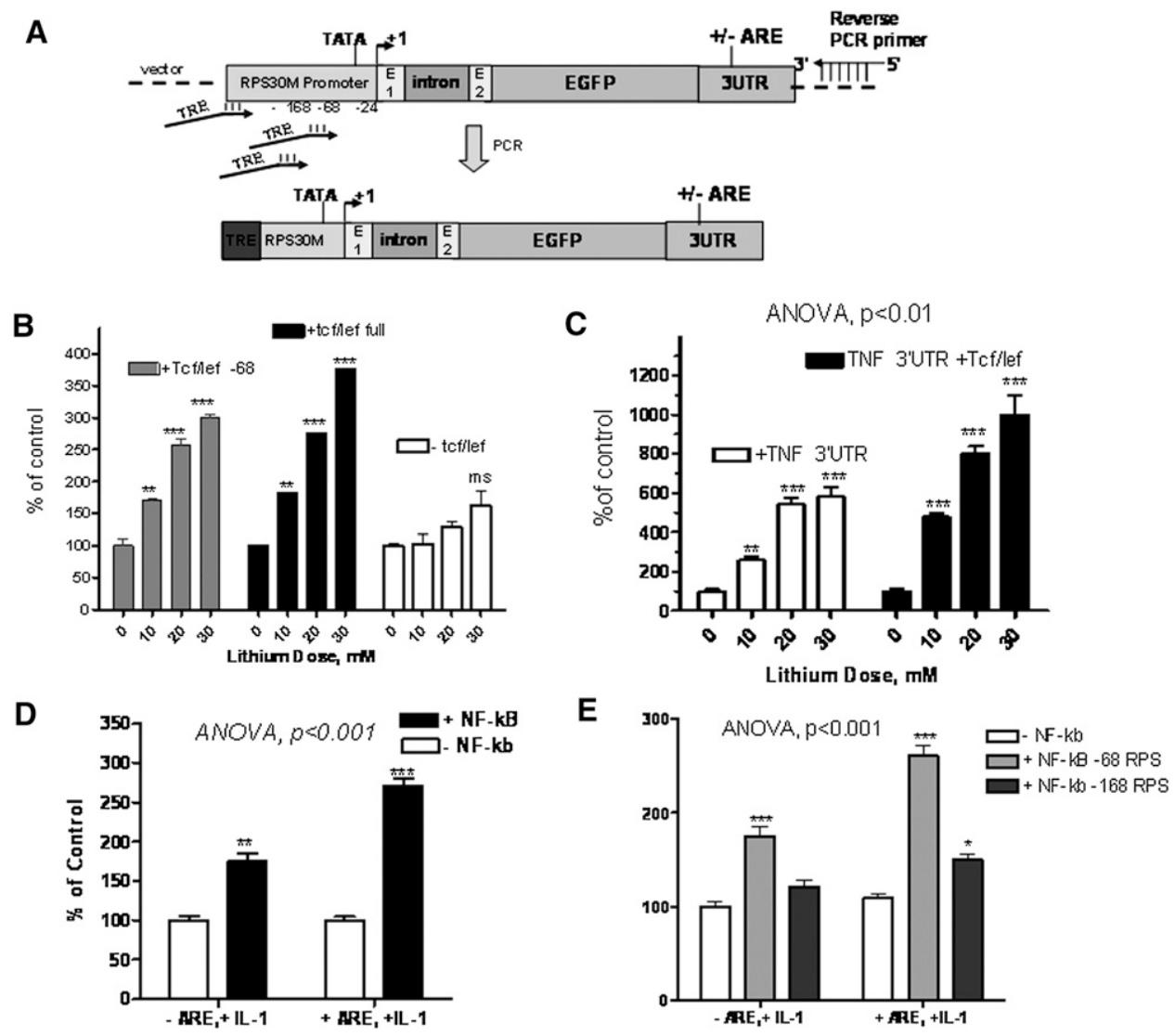

FIGURE 5. Coupled transcriptional and post-transcriptional regulation. (A) Schematic diagram showing the generation of PCR products employing the cloning-free method (al-Haj et al. 2009) in which the forward primer contains the transcriptional response element (TRE) of interest at the $5^{\prime}$-end and the $3^{\prime}$-end part is a sequence target specific location of the promoter. Nucleotide number shown is in relation to the TATA signal. The 3'UTR is with or without ARE. $(B)$ Lithium dose-dependent induction of reporter activity due to the RPS30M promoter that was generated by PCR using a forward primer that has two copies of Tcf/lef and a partial RPS30M promoter ( -68 ; left columns) or the full promoter (middle columns). A construct without Tcf/lef was used as a control (right columns). (C) Coupled transcriptional and posttranscriptional effects due to Tcf/lef TRE and TNF- $\alpha$ 3'UTR. Cells were transfected with the reporter constructs with TNF $3^{\prime}$ UTR in the absence (left side) or the presence of Tcf/lef TRE in the RPS30M promoter of the constructs (right side); cells were treated with lithium for $18 \mathrm{~h}$. The control is $100 \%$ of reporter activity with no Li treatment. (D) Coupled transcriptional and post-transcriptional effects due to NF- $\kappa \mathrm{B}$ signaling. Cells were transfected with the reporter construct with IL-8 3'UTR (ARE, right side) or without (-ARE, left side) in the absence or presence of NF-кB TRE sites in the RPS30M promoter of the constructs. Reporter activity in the absence of IL- $1 \alpha(10 \mathrm{ng} / \mathrm{mL})$ was taken as control of $100 \%$. (E) Cells were transfected with the reporter construct containing the TNF- $\alpha 3^{\prime} \mathrm{UTR}$ (ARE) in the absence or the presence of two copies of NF- $\kappa B$ constructs in -68 RPS30M and -168 RPS30M. Reporter activity in the absence of IL-1 $\alpha(10 \mathrm{ng} / \mathrm{mL})$ was taken as a control of $100 \%$. Data above are mean \pm SEM (triplicate readings) of quantitated captured images from one experiment of at least three independent experiments. $P$-values: ${ }^{\star} P<0.05,{ }^{\star *} P<0.01,{ }^{* *} P<0.001$. ms: Marginally significant.

of TetO-mediated shutoff. The activity of the EGFP reporter from the TetO -24 RPS30 and TetO -68 RPS30 constructs was reduced by $71 \%$ and $84 \%$ when the cells were treated with doxycycline before transfection (Fig. 6A). We selected the TetO -68 RPS30 for the doxycycline chase experiment where cells were first transfected overnight to allow the reporter expression. At 24-h post-doxycycline treatment, a $60 \%-80 \%$ reduction of reporter activity was detected in the case of ARE 3'UTRs that represent unstable mRNAs (Fig. 6C) compared with the control stable 3'UTRlinked reporter, which was reduced by $\sim 30 \%$ (the half-life of the expressed EGFP $>20 \mathrm{~h}$ ). These conditions allowed optimal differential results between the constructs with stable mRNA and unstable mRNA (Fig. 6C). The use of the
PCR-facilitated inclusion of TetO without cloning indicates the versatility of the RPS30M-driven plasmid with any ARE or 3'UTR of interest.

If mRNA half-life determinations are required, then the TetO-RPS30M can be used for this purpose, instead of using transcriptional inhibitors, such as actinomycin $\mathrm{D}(\mathrm{AcD})$ that can perturb the normal biology of RNA stability and cause nonspecific toxicity (Harrold et al. 1991; Rajagopalan and Malter 1996; Blaxall and Port 2000). Indeed, the TetOlinked system has been well developed and used extensively for mRNA half-life determinations (Xu et al. 1998; Loflin et al. 1999; Chang et al. 2004; Tchen et al. 2004; Chen et al. 2007, 2008, 2009; Winzen et al. 2007). Thus, we have carried out mRNA half-life determinations showing the utility of 
A

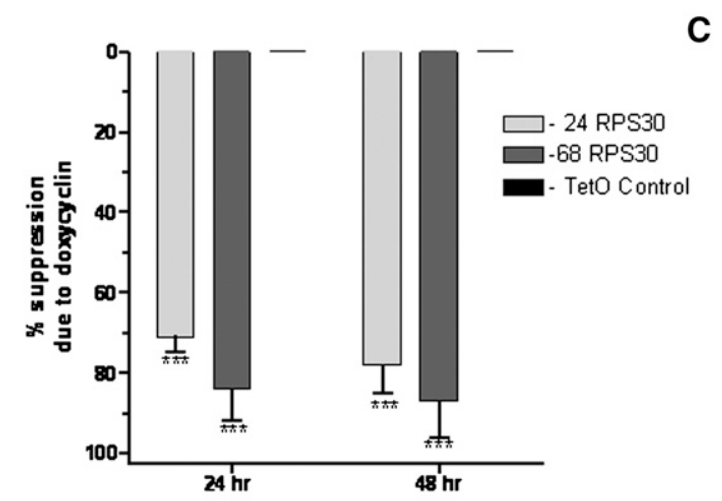

B

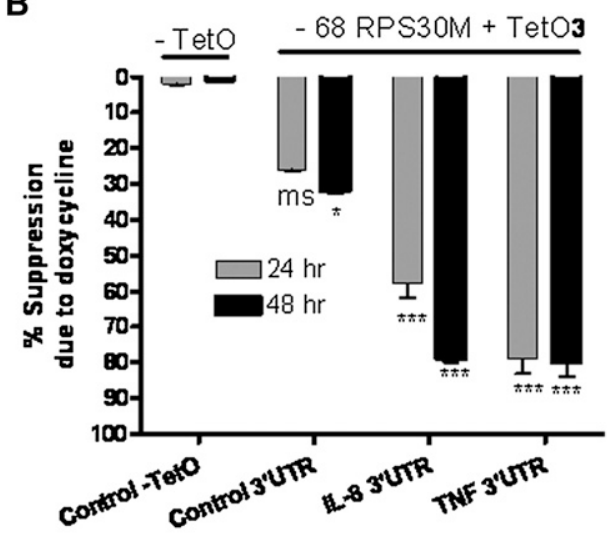

C

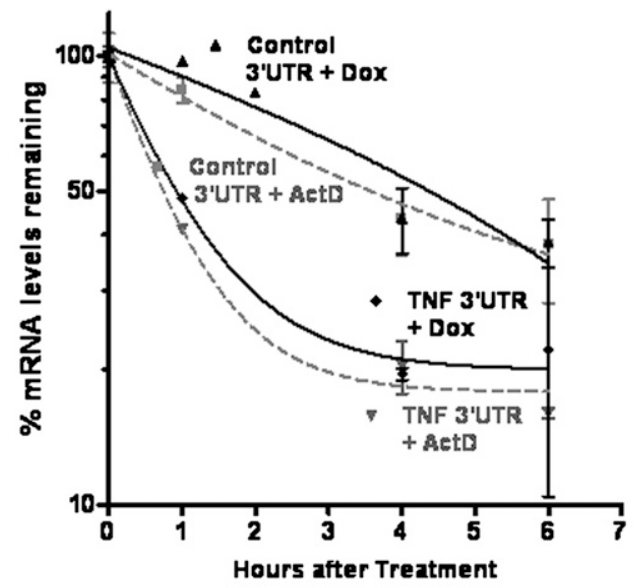

D

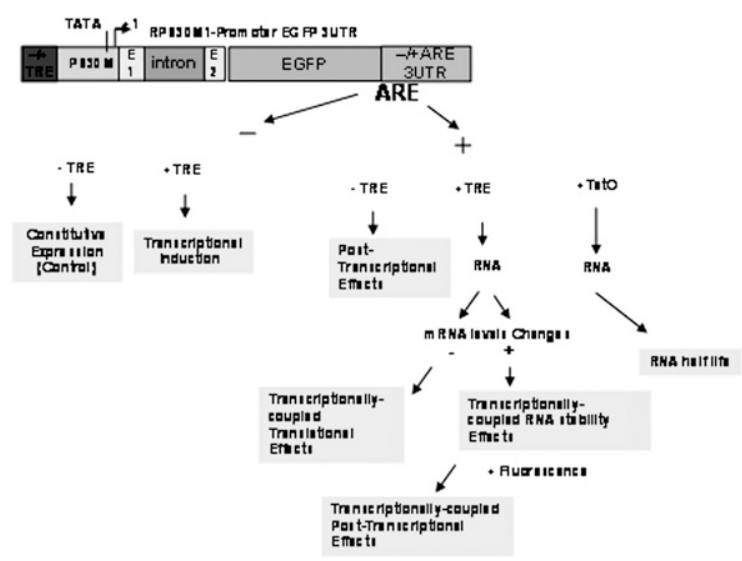

FIGURE 6. TetO-regulated RPS30M-linked EGFP for specific assessment of post-transcriptional regulation and half-life determinations. $(A, B)$ TetOconversion of RPS30M into TetO-regulated constructs using a cloning-free approach (Fig. 5A). HeLa-Tet off cells in 96-well microplate were transfected

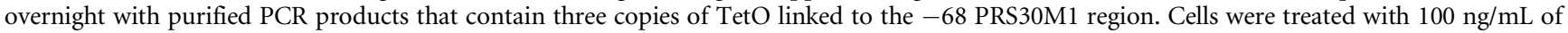
doxycycline for $30 \mathrm{~h}$. Reporter activity as fluorescence was assessed from processed images captured by a BD Bioimager and quantitated by ProXcell. Data are mean \pm SEM (quadruplicate) of one experiment of two. ${ }^{\star} P<0.01,{ }^{* * *} P<0.001$, ms: marginally significant. (C) Half-life measurements using doxycycline $(1 \mu \mathrm{g} / \mathrm{mL})$ or actinomycin $\mathrm{D}(10 \mu \mathrm{g} / \mathrm{mL})$ that shut off transcription from TetO-linked RPS30M reporters with or without AU-rich elements. Decay curves of two constructs are shown using one phase decay model. Data are mean \pm SEM (triplicate) of one representative experiment of two performed. (D) An overall scheme of the transcriptional/post-transcriptional assessment using the RPS30 reporter system. ARE: AU-rich elements; TRE: transcriptional response elements; Dox: doxycyline; and AcD: actinomycin D.

the cloning-free construction of TetO-RPS30M and response to doxycycline-mediated shut-off transcription (Fig. $6 \mathrm{~B})$. The half-life of the reporter mRNA linked to TNF $3^{\prime} \mathrm{UTR}$ was $0.55 \mathrm{~h}$, which is significantly shorter than the reporter mRNA with the control $3^{\prime} \mathrm{UTR}(>5 \mathrm{~h})$ and correlated with the protein levels modulated by doxycycline. However, we always detect basal levels of unstable transcripts of $\sim 20 \%$ from $6 \mathrm{~h}$ and even after $8 \mathrm{~h}$ of doxycycline treatment suggesting potential leakiness in transcription. This limitation may be circumvented with usage of more than three copies of TetO-though this has not been evaluated in this system. We used AcD to block transcription and performed experiments using doxycycline and an $\mathrm{AcD}$ chase in parallel, in which comparable results were observed (Fig. 6B). Thus, the leakiness is not always detectable with the Northern blotting method, which has been previously used with the Tet system, compared with the highly sensitive quantitative PCR (QPCR) that has a much lower threshold of detecting a mRNA copy number. Thus, in the case of sensitive QPCR, it is advisable to use the mRNA decay curve fit and mRNA half-life determination that consider plateaus, such as the one-phase decay model (Khabar et al. 2003; Al-Ahmadi et al. 2009). Figure 6D shows an overall scheme of the RPS30M system versatility.

The use of a fluorescence-based reporter system employing a modified ribosomal protein gene promoter (RPS30M), which is constitutively active and not subject to promoter stimulation, allows its use as a simpler approach compared with RNA-based assessment that requires RNA extraction, use of transcriptional inhibitors, and RNA quantification. The RPS30M system with a fluorescence end point, or other detection reporters, such as luciferase, allows the assessment of the integrated outcome of mRNA stability and translation, and thus, it is more relevant in 
drug screening approaches. Different in-depth analyses can also be performed with the RPS30M promoter-driven system. Using the EGFP based assay and the Taqman RTPCR permits analysis of mRNA stabilization and the regulation of translation of a single reporter assay. The mRNA half-life determination is simplified with a strategy that utilizes the simple cloning-free approach of the TetO-mediated transcriptional block. Individual or coupled transcriptional/post-transcriptional effects due to a single transcriptional factor response element can also be performed with the cloning-free approach.

\section{MATERIALS AND METHODS}

\section{Cloning of the ribosomal protein and other cellular promoters}

The EGFP-Gwiz plasmid, which is under the control of CMV/ Intron A, was obtained from Genlantis. The plasmid backbone was used to construct different promoters in place of the CMV promoter/Intron A cassette, which was removed by using inverse PCR with forward primer TCTTTTCTGCAGTCACCGTC and reverse primer CACTATGATATCTGTGCGGTATTTCACAC that contains an EcoRV site (underlined). Ribosomal protein promoters were amplified from the genomic DNA of the HEK293 cell line, whereas SV40 and EF promoters were cloned from SV40 pGL3 (Promega, Inc.) and pORF (Invitrogen) plasmids, respectively. The promoters with or without their introns were amplified from genomic DNA using PCR with primers specific to the flanking region of each promoter/intron sequence of the following genes: PRPLO, PRPL1, RPL3, RPS23, and RPS30. The gene structures of the ribosomal promoters were obtained from the Ribosomal Protein Database (http://ribosome.med.miyazaki-u.ac.jp). The forward and reverse primers, depending on the orientation of the promoters in the genomic DNA, included the restriction sites, EcoRV and SalI sites. PCR was carried out with the proofreading $P f u$ polymerase (Stratagene). Amplified DNA fragments were resolved in $1.2 \%-1.5 \%$ agarose gel and the desired amplicons were excised, purified, and cloned into the promoterless GwizEGFP backbone. All the promoters including SV40 and pEF promoters were cloned into the same vector backbone.

\section{Modification of the RPS23 and RPS30 promoters}

A 5 '-truncated RPS23M promoter (480 bases) with first exon and intron (501 bases) was constructed by custom gene synthesis (GeneArt, Inc.). A 5' addition of 68 bases of Sp1 site-containing sequences of RPS23 (+806 to +872 from TSS) was included and nine bases of RPS23 exon 2 were added for splicing. The ATG site in exon 1 of RPS23 was mutated to CTG to force translation initiation of the linked EGFP reporter. The RPS30M promoter construct was synthesized by GeneArt and contains a $5^{\prime}$-truncated RPS30 promoter ( 418 bases), first exon ( 45 bases), first intron ( 268 bases), and exon 2 (eight bases) for splicing. The EGFP coding region was fused with exon 2 of the RPS. The putative TATA box was improved from TACAAATA to TATAAATA. BamH1 site CACTGAG was eliminated by mutating to CACCTTGAG since this site is used for $3^{\prime} \mathrm{UTR}$ cloning. The RPS30M promoter now contains three sp1 sites.

\section{Cloning of AU-rich regions and ARE}

The AU-rich 237-bp region (972-1209 nt: NM_000584) that belongs to the 1250-bp IL-8 $3^{\prime}$ UTR or 250 bases from TNF- $\alpha$ 3'UTR (1200-1450 bp, NM_00059) were amplified by RT-PCR using specific forward and reverse primers with additional $5^{\prime}$ sequences that contain BamHI and $\mathrm{XbaI}$, respectively. The forward primer is $5^{\prime}$-CAGCAGGATCCGATGTTGTGAGGACAT GTG- $3^{\prime}$ and the reverse primer is $5^{\prime}$-CGACCTCTAGAACCC TGATTGAAATTTAT-3' for IL-8 3' UTR. For TNF- $\alpha$ 3'UTR, the forward primer is $5^{\prime}$-CAGCAGGATCCAGAATGCTGCAGGA CTTGAG- $3^{\prime}$ and the reverse primer is $5^{\prime}$-CGACCTCTAGACTAT TGTTCAGCTCCGTTT- $3^{\prime}$. The PCR products were cut by BamHI and XbaI sequentially and followed by phenol extraction and ethanol precipitation. Short DNA duplexes were made by annealing two synthetic complementary oligonucleotides of 70 bases that correspond to TNF- $\alpha$ ARE or a mutant form with BamHI and XbaI overhangs. The TNF- $\alpha$ oligonucleotide ARE sequence is GATCCTTGTGATTATTTATTATTTATTTATTATTTATTTATTT ACAGATGAATGTATTTATTTGGGAGAT and their mutant forms (ATT to CCG). The purified DNA products were ligated into the RPS30M or CMV promoter expression vectors with bovine growth hormone 3'UTR that has BamHI and XbaI sites. Recombinant colonies were verified by PCR and sequencing.

\section{Cell lines, compounds, and RNA-binding protein plasmids}

The HEK293 cell line was obtained from American Type Culture Collection (ATCC) and cultured in DMEM medium (Invitrogen) supplemented with $10 \%$ FBS and antibiotics. The Tet-off HeLa cell line was obtained from Clontech and was maintained in DMEM with selection drug G418 (Sigma). The Huh-7 cell line was propagated in DMEM medium with $10 \%$ FBS and antibiotics. The following are the stimuli and compounds that were used in this study: Recombinant human IL- $1 \alpha$ (R\&D Systems, Inc.), TNF$\alpha$ (R\&D systems), okadaic acid (Calbiochem), poly I.C. (Calbiochem), calyculin (Sigma-Aldrich), doxycycline (Sigma), cobalt chloride (Sigma), PMA (Sigma), ionomcyin (Sigma), lithium (Sigma), ansiomycin (Santa Cruz Biotech), hydrogen peroxide (Sigma), actinomycin D (Sigma), and doxycycline (Sigma). The RNA-binding protein expression plasmids, HuR and mutant C124R TTP, were kindly provided by Dr. Christopher Moroni (University of Basel) and Dr. Perry Blackshear (NIH), respectively.

\section{Reporter transfection and reporter activity assessment}

Cells in 96-well clear bottom black microplates were transfected with 50-100 ng of the reporter vectors using lipofectamine 2000 reagent (Invitrogen). All transfections were performed in several replicates as indicated in the text. The variance in GFP fluorescence among replicate microwells was $<6 \%$; thus, with this minimum variance, experiments do not warrant transfection normalization (Al-Zoghaibi et al. 2007). Automated laser-focus image capturing was performed using the high-throughput BD Pathway 435 imager (BD Biosciences). Image processing, segmentation, and fluorescence quantification were facilitated by the ProXcell program and previously described (al-Haj et al. 2009). Data are presented as mean values \pm standard error (SEM) of 
total fluorescence intensity in each well with replicate readings ranging from three to four as indicated in the text. Student's $t$-test was used when comparing two data groups, while analysis of variance (ANOVA) was performed for each data set having three or more data groups.

\section{RNA, reverse transcription, and $R T-P C R$}

For total RNA preparations, transfections were performed in $10-\mathrm{cm}$ plates with $4 \mu \mathrm{g}$ vector DNA using lipofectamine 2000. After $24 \mathrm{~h}$, the cells were split into six-well plates to ensure equal proportions of transfected cells in each plate. Total RNA was extracted with TRI Reagent (Sigma). Reverse transcription was performed using Superscript II and Oligo dT primer (Invitrogen). RT-PCR was performed using a custom-made Taqman primer and probe set (Applied Biosystems). The primers span the RPS30M intron to control DNA contamination. The 6-carboxyfluorescein (6FAM)labeled TaqMan probe that targets the CMV exon 1-EGFP (exon 2) junction sequence was used. The probe design allowed further control of DNA contamination. The control RPL0 mRNA probe is labeled with a 5' reporter VIC dye (Applied Biosystems). The specificity for the cDNA of the Taqman primer was tested on a negative control containing plasmid DNA. The endogenous control RPLP0 was used for normalization. RT-PCR was performed in multiplex in the Chroma 4 DNA Engine cycler (BioRad). Cellculture experiments for the mRNA half-life determination were performed with the HeLa Tet-off cell line that was treated with doxycycline $(1 \mu \mathrm{g} / \mathrm{mL})$ to shut off transcription.

\section{Transcriptional coupling and TetO conversion of RPS30M promoter}

The RPS30M promoter-linked EGFP expression construct was turned transcriptionally inducible by generating an expression active PCR product directly from the vector using two primers flanking the full expression cassette. The forward primer has 1718 bases of complementary sequence to the RPS30M plasmid template (full RPS30M promoter, -68 , or -168 from the TATA box) and $5^{\prime}$-end sequences that contain transcriptional response elements. The TREs used were three copies of the Tcf/lef binding site TTTAAAGATCAAAG, NF- $\kappa$ B site AGGGGACTTTCCTGA, or TetO CATCCCTATCAGTGATAGAC. The reverse primer is complementary to a downstream region of the poly(A) site. PCRs were carried out using the following reagents and conditions: 2.5 U HotStart Taq (Qiagen) and 0.2 U Pfx polymerase (Invitrogen) mix, $2 \mu \mathrm{L}$ (100-200 ng) of the vector template, 1X PCR buffer, $0.2 \mathrm{mM}$ dNTPs, and $0.2 \mu \mathrm{M}$ primers, with the following cycle conditions: $95^{\circ} \mathrm{C}$ for $12 \mathrm{~min} ; 31$ cycles of: $94^{\circ} \mathrm{C}, 1 \mathrm{~min} ; 51^{\circ} \mathrm{C}$, $1 \mathrm{~min} ; 72^{\circ} \mathrm{C}, 4 \mathrm{~min}$; and final extension at $72^{\circ} \mathrm{C}$ for $7 \mathrm{~min}$. The PCR products were purified using PCR purification columns (Qiagen) to eliminate the primers, small PCR products, buffer, and enzymes. The PCR products were finally eluted in sterile water. The PCR products were run on a $1.2 \%$ agarose gel and visualized by ethidium bromide under UV light to verify size and quality.

\section{ACKNOWLEDGMENTS}

The study is supported by intramural funding from the King Faisal Specialist Hospital and Research Center Organization to the BioMolecular Research Program.
Received December 3, 2009; accepted March 5, 2010.

\section{REFERENCES}

Ait-Goughoulte M, Banerjee A, Meyer K, Mazumdar B, Saito K, Ray RB, Ray R. 2009. Hepatitis C virus core protein interacts with fibrinogen- $\beta$ and attenuates cytokine stimulated acute-phase response. Hepatology doi: 10.1002/hep.23502.

Al-Ahmadi W, Al-Ghamdi M, Al-Haj L, Al-Saif M, Khabar KS. 2009. Alternative polyadenylation variants of the RNA binding protein, HuR: Abundance, role of AU-rich elements and auto-regulation. Nucleic Acids Res 37: 3612-3624.

al-Haj L, Al-Ahmadi W, Al-Saif M, Demirkaya O, Khabar KS. 2009. Cloning-free regulated monitoring of reporter and gene expression. BMC Mol Biol 10: 20. doi: 10.1186/1471-2199-10-20.

Al-Zoghaibi F, Ashour T, Al-Ahmadi W, Abulleef H, Demirkaya O, Khabar KS. 2007. Bioinformatics and experimental derivation of an efficient hybrid $3^{\prime}$ untranslated region and use in expression active linear DNA with minimum poly(A) region. Gene 391: 130-139.

Bartel DP. 2009. MicroRNAs: Target recognition and regulatory functions. Cell 136: 215-233.

Benjamin D, Colombi M, Moroni C. 2004. A GFP-based assay for rapid screening of compounds affecting ARE-dependent mRNA turnover. Nucleic Acids Res 32: e89. doi: 10.1093/nar/gnh086.

Bevan S, Raynes JG. 1991. IL-1 receptor antagonist regulation of acute phase protein synthesis in human hepatoma cells. J Immunol 147: 2574-2578.

Blaxall BC, Port JD. 2000. Determination of mRNA stability and characterization of proteins interacting with adrenergic receptor mRNAs. Methods Mol Biol 126: 453-465.

Briata P, Ilengo C, Corte G, Moroni C, Rosenfeld MG, Chen CY, Gherzi R. 2003. The Wnt/ $\beta$-catenin $\rightarrow$ Pitx2 pathway controls the turnover of Pitx2 and other unstable mRNAs. Mol Cell 12: 12011211.

Chang TC, Yamashita A, Chen CY, Yamashita Y, Zhu W, Durdan S, Kahvejian A, Sonenberg N, Shyu AB. 2004. UNR, a new partner of poly(A)-binding protein, plays a key role in translationally coupled mRNA turnover mediated by the c-fos major coding-region determinant. Genes Dev 18: 2010-2023.

Chen CY, Yamashita Y, Chang TC, Yamashita A, Zhu W, Zhong Z, Shyu AB. 2007. Versatile applications of transcriptional pulsing to study mRNA turnover in mammalian cells. RNA 13: 1775-1786.

Chen CY, Ezzeddine N, Shyu AB. 2008. Messenger RNA half-life measurements in mammalian cells. Methods Enzymol 448: 335-357.

Chen CY, Zheng D, Xia Z, Shyu AB. 2009. Ago-TNRC6 triggers microRNA-mediated decay by promoting two deadenylation steps. Nat Struct Mol Biol 16: 1160-1166.

Chrestensen CA, Schroeder MJ, Shabanowitz J, Hunt DF, Pelo JW, Worthington MT, Sturgill TW. 2004. MAPKAP kinase 2 phosphorylates tristetraprolin on in vivo sites including Ser178, a site required for 14-3-3 binding. J Biol Chem 279: 10176-10184.

Fan J, Heller NM, Gorospe M, Atasoy U, Stellato C. 2005. The role of post-transcriptional regulation in chemokine gene expression in inflammation and allergy. Eur Respir J 26: 933-947.

Franks TM, Lykke-Andersen J. 2007. TTP and BRF proteins nucleate processing body formation to silence mRNAs with AU-rich elements. Genes Dev 21: 719-735.

Gherzi R, Trabucchi M, Ponassi M, Ruggiero T, Corte G, Moroni C, Chen CY, Khabar KS, Andersen JS, BBriat P. 2006. The RNAbinding protein KSRP promotes decay of $\beta$-catenin mRNA and is inactivated by PI3K-AKT signaling. PLoS Biol 5: e5. doi: 10.1371/ journal.pbio.0050005.

Glisovic T, Bachorik JL, Yong J, Dreyfuss G. 2008. RNA-binding proteins and post-transcriptional gene regulation. FEBS Lett 582: 1977-1986.

Halees AS, El-Badrawi R, Khabar KS. 2008. ARED organism: Expansion of ARED reveals AU-rich element cluster variations between human and mouse. Nucleic Acids Res 36: D137-D140. 
Harrold S, Genovese C, Kobrin B, Morrison SL, Milcarek C. 1991. A comparison of apparent mRNA half-life using kinetic labeling techniques vs decay following administration of transcriptional inhibitors. Anal Biochem 198: 19-29.

Hedgepeth CM, Conrad LJ, Zhang J, Huang HC, Lee VM, Klein PS. 1997. Activation of the Wnt signaling pathway: A molecular mechanism for lithium action. Dev Biol 185: 82-91.

Hitti E, Iakovleva T, Brook M, Deppenmeier S, Gruber AD, Radzioch D, Clark AR, Blackshear PJ, Kotlyarov A, Gaestel M. 2006. Mitogen-activated protein kinase-activated protein kinase 2 regulates tumor necrosis factor mRNA stability and translation mainly by altering tristetraprolin expression, stability, and binding to adenine/uridine-rich element. Mol Cell Biol 26: 2399-2407.

Hobert O. 2008. Gene regulation by transcription factors and microRNAs. Science 319: 1785-1786.

Khabar KS. 2005. The AU-rich transcriptome: More than interferons and cytokines, and its role in disease. J Interferon Cytokine Res 25: $1-10$.

Khabar KS, Siddiqui YM, al-Zoghaibi F, al-Haj L, Dhalla M, Zhou A, Dong B, Whitmore M, Paranjape J, Al-Ahdal MN, et al. 2003. RNase L mediates transient control of the interferon response through modulation of the double-stranded RNA-dependent protein kinase PKR. J Biol Chem 278: 20124-20132.

Lai WS, Carballo E, Thorn JM, Kennington EA, Blackshear PJ. 2000. Interactions of $\mathrm{CCCH}$ zinc finger proteins with mRNA. Binding of tristetraprolin-related zinc finger proteins to AU-rich elements and destabilization of mRNA. J Biol Chem 275: 17827-17837.

Lai WS, Parker JS, Grissom SF, Stumpo DJ, Blackshear PJ. 2006. Novel mRNA targets for tristetraprolin (TTP) identified by global analysis of stabilized transcripts in TTP-deficient fibroblasts. Mol Cell Biol 26: 9196-9208.

Lal A, Mazan-Mamczarz K, Kawai T, Yang X, Martindale JL, Gorospe M. 2004. Concurrent versus individual binding of HuR and AUF1 to common labile target mRNAs. EMBO J 23: 3092-3102.

Lasa M, Mahtani KR, Finch A, Brewer G, Saklatvala J, Clark AR. 2000. Regulation of cyclooxygenase 2 mRNA stability by the mitogenactivated protein kinase p38 signaling cascade. Mol Cell Biol 20: 4265-4274.

Lee Y, Sohn WJ, Kim DS, Kwon HJ. 2004. NF-кB- and c-Jundependent regulation of human cytomegalovirus immediate-early gene enhancer/promoter in response to lipopolysaccharide and bacterial CpG-oligodeoxynucleotides in macrophage cell line RAW 264.7. Eur J Biochem 271: 1094-1105.

Loflin P, Chen CY, Shyu AB. 1999. Unraveling a cytoplasmic role for hnRNP D in the in vivo mRNA destabilization directed by the AUrich element. Genes Dev 13: 1884-1897.

Lopez de Silanes I, Galban S, Martindale JL, Yang X, MazanMamczarz K, Indig FE, Falco G, Zhan M, Gorospe M. 2005. Identification and functional outcome of mRNAs associated with RNA-binding protein TIA-1. Mol Cell Biol 25: 9520-9531.

Nott A, Meislin SH, Moore MJ. 2003. A quantitative analysis of intron effects on mammalian gene expression. RNA 9: 607-617.
Pap M, Cooper GM. 1998. Role of glycogen synthase kinase-3 in the phosphatidylinositol 3-kinase/Akt cell survival pathway. J Biol Chem 273: 19929-19932.

Preiss S, Thompson A, Chen X, Rodgers S, Markovska V, Desmond P, Visvanathan K, Li K, Locarnini S, Revill P. 2008. Characterization of the innate immune signalling pathways in hepatocyte cell lines. $J$ Viral Hepat 15: 888-900.

Pshenichkin SP, Wise BC. 1995. Okadaic acid increases nerve growth factor secretion, mRNA stability, and gene transcription in primary cultures of cortical astrocytes. J Biol Chem 270: 59945999.

Rajagopalan LE, Malter JS. 1996. Turnover and translation of in vitro synthesized messenger RNAs in transfected, normal cells. J Biol Chem 271: 19871-19876.

Ramanathan M, Hasko G, Leibovich SJ. 2005. Analysis of signal transduction pathways in macrophages using expression vectors with CMV promoters: A cautionary tale. Inflammation 29: 94 102.

Stoecklin G, Tenenbaum SA, Mayo T, Chittur SV, George AD, Baroni TE, Blackshear PJ, Anderson P. 2008. Genome-wide analysis identifies interleukin-10 mRNA as target of tristetraprolin. J Biol Chem 283: 11689-11699.

Tchen CR, Brook M, Saklatvala J, Clark AR. 2004. The stability of tristetraprolin mRNA is regulated by mitogen-activated protein kinase p38 and by tristetraprolin itself. J Biol Chem 279: 3239332400 .

Vasudevan S, Tong Y, Steitz JA. 2007. Switching from repression to activation: MicroRNAs can up-regulate translation. Science 318: 1931-1934.

Wang SW, Pawlowski J, Wathen ST, Kinney SD, Lichenstein HS, Manthey CL. 1999. Cytokine mRNA decay is accelerated by an inhibitor of p38-mitogen-activated protein kinase. Inflamm Res 48: $533-538$.

Winzen R, Kracht M, Ritter B, Wilhelm A, Chen CY, Shyu AB, Müller M, Gaestel M, Resch K, Holtmann H. 1999. The p38 MAP kinase pathway signals for cytokine-induced mRNA stabilization via MAP kinase-activated protein kinase 2 and an AU-rich regiontargeted mechanism. EMBO J 18: 4969-4980.

Winzen R, Thakur BK, Dittrich-Breiholz O, Shah M, Redich N, Dhamija S, Kracht M, Holtmann H. 2007. Functional analysis of KSRP interaction with the AU-rich element of interleukin-8 and identification of inflammatory mRNA targets. Mol Cell Biol 27: 8388-8400.

Xu N, Loflin P, Chen CY, Shyu AB. 1998. A broader role for AU-rich element-mediated mRNA turnover revealed by a new transcriptional pulse strategy. Nucleic Acids Res 26: 558-565.

Zhang R, Su B. 2009. Small but influential: The role of microRNAs on gene regulatory network and 3'UTR evolution. J Genet Genomics 36: $1-6$.

Zhang T, Kruys V, Huez G, Gueydan C. 2002. AU-rich elementmediated translational control: Complexity and multiple activities of trans-activating factors. Biochem Soc Trans 30: 952-958. 

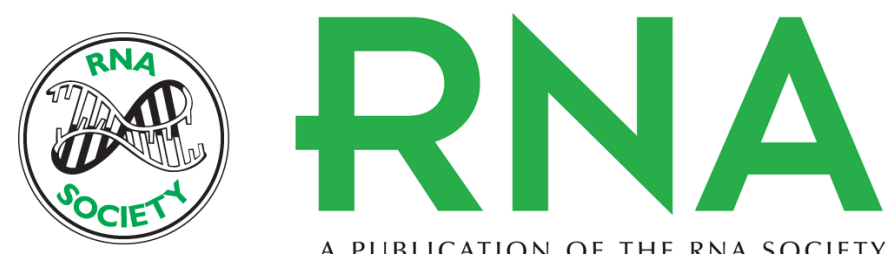

A PUBLICATION OF THE RNA SOCIETY

\section{A versatile ribosomal protein promoter-based reporter system for selective assessment of RNA stability and post-transcriptional control}

Edward Hitti, Suhad Al-Yahya, Maher Al-Saif, et al.

RNA 2010 16: 1245-1255 originally published online April 23, 2010

Access the most recent version at doi:10.1261/rna.2026310

\section{References This article cites 46 articles, 24 of which can be accessed free at: http://rnajournal.cshlp.org/content/16/6/1245.full.html\#ref-list-1}

Open Access Freely available online through the RNA Open Access option.

License Freely available online through the RNA Open Access option.

Email Alerting Receive free email alerts when new articles cite this article - sign up in the box at the Service top right corner of the article or click here.

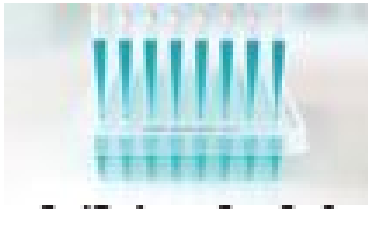

Providing Precise Solutions for your research.

To subscribe to RNA go to:

http://rnajournal.cshlp.org/subscriptions 